\title{
Alcohol Dependence and Withdrawal Impair Serotonergic Regulation of GABA Transmission in the Rat Central Nucleus of the Amygdala
}

\author{
${ }^{D}$ Sophia Khom, Sarah A. Wolfe, ${ }^{\circledR}$ Reesha R. Patel, Dean Kirson, David M. Hedges, Florence P. Varodayan, \\ ${ }^{(-)}$Michal Bajo, and ${ }^{\circledR}$ Marisa Roberto \\ Department of Molecular Medicine, The Scripps Research Institute, La Jolla, California 92307
}

Excessive serotonin (5-HT) signaling plays a critical role in the etiology of alcohol use disorder. The central nucleus of the amygdala (CeA) is a key player in alcohol-dependence associated behaviors. The CeA receives dense innervation from the dorsal raphe nucleus, the major source of 5-HT, and expresses 5-HT receptor subtypes (e.g., 5-HT2C and 5-HT1A) critically linked to alcohol use disorder. Notably, the role of 5-HT regulating rat CeA activity in alcohol dependence is poorly investigated. Here, we examined neuroadaptations of CeA 5-HT signaling in adult, male Sprague Dawley rats using an established model of alcohol dependence (chronic intermittent alcohol vapor exposure), ex vivo slice electrophysiology and ISH. 5-HT increased frequency of sIPSCs without affecting postsynaptic measures, suggesting increased CeA GABA release in naive rats. In dependent rats, this 5-HT-induced increase of GABA release was attenuated, suggesting blunted CeA 5-HT sensitivity, which partially recovered in protracted withdrawal (2 weeks). 5-HT increased vesicular GABA release in naive and dependent rats but had split effects (increase and decrease) after protracted withdrawal indicative of neuroadaptations of presynaptic 5HT receptors. Accordingly, 5-HT abolished spontaneous neuronal firing in naive and dependent rats but had bidirectional effects in withdrawn. Alcohol dependence and protracted withdrawal did not alter either 5-HT1A-mediated decrease of CeA GABA release or Htr1a expression but disrupted 5-HT2C-signaling without affecting Htr2c expression. Collectively, our study provides detailed insights into modulation of CeA activity by the 5-HT system and unravels the vulnerability of the CeA 5HT system to chronic alcohol and protracted withdrawal.

Key words: alcohol use disorder; central amygdala; electrophysiology; ethanol; GABA; serotonin

Significance Statement

Elevated GABA signaling in the central nucleus of the amygdala $(\mathrm{CeA})$ underlies key behaviors associated with alcohol dependence. The CeA is reciprocally connected with the dorsal raphe nucleus, the main source of serotonin (5-HT) in the mammalian brain, and excessive 5-HT signaling is critically implicated in the etiology of alcohol use disorder. Our study, using a well-established rat model of alcohol dependence, ex vivo electrophysiology and ISH, provides mechanistic insights into how both chronic alcohol exposure and protracted withdrawal dysregulate 5-HT signaling in the CeA. Thus, our study further expands our understanding of CeA cellular mechanisms involved in the pathophysiology of alcohol dependence and withdrawal.

Received Mar. 30, 2020; revised July 8, 2020; accepted July 14, 2020.

Author contributions: S.K. and M.R. designed research; S.K., S.A.W., R.R.P., D.K., D.M.H., F.P.V., and M.B. performed research; S.K., S.A.W., R.R.P., D.K., D.M.H., F.P.V., and M.B. analyzed data; S.K. wrote the first draft of the paper; S.K., S.A.W., R.R.P., D.K., D.M.H., F.P.V., M.B., and M.R. edited the paper.

The authors declare no competing financial interests.

This work was supported by National Institutes of Health/National Institute on Alcohol Abuse and Alcoholism Grants AA006420, AA013498, AA015566, AA017477, AA027700, AA007456, and AA021491, all to M.R., Grant AA026865 to R.R.P., Grants AA025262 and AA026638 to D.K., and Grant AA025408 to F.P.V.; and Pearson Center for Alcoholism and Addiction Research and the Austrian Science Fund FWF Erwin Schrödinger Fellowship J-3942-B30 to S.K. This is Scripps manuscript number 29963.

Correspondence should be addressed to Marisa Roberto at mroberto@scripps.edu.

https://doi.org/10.1523/JNEUROSCI.0733-20.2020

Copyright $\odot 2020$ the authors

\section{Introduction}

Alcohol use disorder (AUD) is a chronic, relapsing disease characterized by compulsive alcohol seeking and taking, loss of control in limiting alcohol intake, and the emergence of negative emotional states during absence from alcohol (Koob, 2008; Spanagel et al., 2014; Koob and Volkow, 2016). These states are regulated by specific neurochemical systems modulating neurocircuits involved in drug reward, negative affect, and executive control (Wise and Koob, 2014). Excessive serotonin (5-hydroxytryptamine [5-HT]) signaling has been implicated in the etiology of AUD and can elicit craving in abstinent patients (Krystal et al., 1996; Pettinati et al., 2003; Bonkale et al., 2006; Kranzler et 
al., 2013; Marcinkiewcz et al., 2016). Specifically, polymorphisms in genes encoding for distinct components of the 5HT system are either predisposing to the development of AUD or are linked to specific behaviors associated with AUD (Lappalainen et al., 1998; Feinn et al., 2005; Yohros et al., 2018). Accordingly, drugs modulating 5-HT signaling have been shown to decrease alcohol intake in both humans and animal models (Lê et al., 1996; Lejoyeux, 1996; Belmer et al., 2016; Dos Santos et al., 2018).

Chronic alcohol exposure alters serotonergic modulation of synaptic transmission and causes potential neuroadaptations in its receptor system (Belmer et al., 2016; Marcinkiewcz et al., 2016). In rodents, both acute alcohol and withdrawal increase excitability of dorsal raphe (DRN) neurons (Lowery-Gionta et al., 2015), thereby likely increasing 5-HT release into DRN-projecting areas. The DRN innervates all major players in the addiction cycle, including the central nucleus of the amygdala (CeA) (Vertes, 1991; Retson and Van Bockstaele, 2013; Linley et al., 2016). The CeA serves as an integrative hub mediating key aspects of negative emotional states associated with alcohol dependence, including anxiety-like behaviors (Gilpin et al., 2015). The CeA is a mainly GABAergic nucleus, particularly sensitive to both acute and chronic ethanol (Roberto et al., 2003, 2004, 2020). Thus, elevated CeA GABA transmission is a characteristic of alcohol dependence across species, including humans (Roberto et al., 2004; Herman et al., 2016; Augier et al., 2018; Jimenez et al., 2019). Importantly, acute alcohol administration enhances 5-HT release in the CeA (Yoshimoto et al., 2000).

The 5-HT receptor system comprises 14 different 5-HT-activated either inhibitory (5-HT1 receptor subtypes) or excitatory (5-HT2, 4, 6, and 7 receptor subtypes) receptors coupled to Gproteins and an excitatory ligand-gated ion channel (5-HT3) (McCorvy and Roth, 2015). 5-HT receptor subtypes are abundantly expressed in the mammalian brain (Charnay and Léger, 2010), tightly regulating 5-HT signaling (Belmer et al., 2016). Multiple studies implicate a critical role of 5-HT1A and 5-HT2C signaling in the extended amygdala in addictive behaviors, including AUD (Müller et al., 2007; Marcinkiewcz et al., 2016). For instance, site-specific injections of 5-HT2C antagonists into the nucleus accumbens shell block escalation of alcohol intake in rodents (Yoshimoto et al., 2012). Alcohol dependence elicits specific changes in 5HT2C signaling conferring neuronal hyperexcitability in the ventral BNST (Marcinkiewcz et al., 2015) and increased amygdalar 5-HT2C expression was observed in genetic models of alcohol preference (Pandey et al., 1996) corroborating a critical role for 5-HT2C in excessive alcohol intake. Last, 5-HT induces anxiety-like behavior in the dorsal BNST via activation of 5-HT1A (Garcia-Garcia et al., 2018).

However, despite strong serotonergic innervation of the CeA (Vertes, 1991; Retson and Van Bockstaele, 2013; Linley et al., 2016) accompanied by dense expression of 5-HT2C and 5-HT1A (Asan et al., 2013), little is known about 5-HT regulation of $\mathrm{CeA}$ activity under physiological (naive) conditions and/or alcohol dependence and protracted withdrawal. Thus, we examined potential neuroadaptations of the CeA 5HT system induced by alcohol dependence using a rat model of chronic intermittent vapor exposure, ex vivo slice electrophysiology, and ISH. Specifically, we studied 5-HT-modulation of $\mathrm{CeA} \mathrm{GABA}_{\mathrm{A}}$ receptor-mediated synaptic transmission, 5-HT effects on spontaneous neuronal firing, and expression of Htrla and Htr $2 c$ mRNA accompanied by functional assessment of 5-HT1A and 5-HT2C signaling in naive, dependent, and withdrawn rats.

\section{Materials and Methods}

All procedures were approved by the Scripps Research Institutional Animal Care and Use Committee and are in line with the National Institutes of Health Guide for the care and use of laboratory animals.

For this study, we used a total of 119 male Sprague Dawley rats (Charles River) weighing 225-250 g on arrival. Rats were group-housed ( 2 or 3 per cage) in standard plastic cages in a temperature- and humidity-controlled room and were maintained under a reverse $12 \mathrm{~h} / 12 \mathrm{~h}$ light/dark cycle with ad libitum access to food and water.

Chronic intermittent alcohol exposure

To induce alcohol dependence, 57 rats were exposed to $14 \mathrm{~h} /$ day alcohol vapor (10 h air) using the standard chronic intermittent alcohol inhalation method in their home cages. Blood alcohol levels were determined 1 or 2 times per week from tail-blood samples (average blood alcohol level: $151 \pm 7 \mathrm{mg} / \mathrm{dl}$ ). Twenty-five dependent rats were subsequently subjected to protracted withdrawal for 2 weeks. Naive controls were treated similarly, except that they were exposed to air only.

\section{Slice electrophysiology}

Preparation of acute brain slices and electrophysiological recordings were performed as previously described (Roberto et al., 2004; Tunstall et al., 2019; Khom et al., 2020). We decapitated deeply anesthetized rats (3$5 \%$ isoflurane anesthesia) and rapidly isolated their brains in ice-cold oxygenated high-sucrose cutting solution (composition in mM as follows: 206 sucrose, $2.5 \mathrm{KCl}, 0.5 \mathrm{CaCl}_{2}, 7 \mathrm{MgCl}_{2}, 1.2 \mathrm{NaH}_{2} \mathrm{PO}_{4}, 26$ $\mathrm{NaHCO}_{3}, 5$ glucose, and 5 HEPES); 300- $\mu$ m-thick coronal slices containing the medial subdivision of CeA were cut using a VT $1000 \mathrm{~S}$ vibratome (Leica Microsystems) and incubated for $30 \mathrm{~min}$ in warm $\left(37^{\circ} \mathrm{C}\right.$ ), oxygenated aCSF (composition in $\mathrm{mm}$ as follows: $130 \mathrm{NaCl}$, $3.5 \mathrm{KCl}, 2 \mathrm{CaCl}_{2}, 1.25 \mathrm{NaH}_{2} \mathrm{PO}_{4}, 1.5 \mathrm{MgSO}_{4}, 24 \mathrm{NaHCO}_{3}$, and 10 glucose) followed by another $30 \mathrm{~min}$ incubation at room temperature. Dependent rats were euthanized during the last hour of their daily alcohol vapor exposure. Slices were cut and incubated in ethanol-free solutions; thus, the slices from dependent animals underwent acute in vitro withdrawal (1-10 h).

We recorded from neurons located in the medial subdivision of the CeA using either whole-cell voltage clamp or cell-attached current-clamp mode. Neurons were visualized with infrared differential interference contrast optics using a $40 \times$ water-immersion objective (Olympus BX51WI), and a CCD camera (EXi Aqua, QImaging). All recordings were performed in gap-free acquisition mode with a $10 \mathrm{kHz}$ sampling rate and $10 \mathrm{kHz}$ low-pass filtering using a MultiClamp700B amplifier, Digidata 1440A, and pClamp 10 software (Molecular Devices).

Patch pipettes were pulled from borosilicate glass (3-5 $\mathrm{m} \Omega$, King Precision) and filled with a $\mathrm{KCl}$-based internal solution (composition in mM as follows: $135 \mathrm{KCl}, 5 \mathrm{EGTA}, 5 \mathrm{MgCl}_{2}, 10 \mathrm{HEPES}, 2 \mathrm{Mg}$-ATP, and 0.2 Na-GTP, pH 7.2-7.4, adjusted with $1 \mathrm{M} \mathrm{KOH,} \mathrm{290-300} \mathrm{mOsm)} \mathrm{for}$ whole-cell recordings or a K-gluconate-based internal solution (composition in $\mathrm{mm}$ as follows: $145 \mathrm{~K}$-gluconate, $0.5 \mathrm{EGTA}, 2 \mathrm{MgCl}_{2}, 10$ HEPES, $2 \mathrm{Mg}$-ATP, and 0.2 Na-GTP, pH7.2-7.4, adjusted with $1 \mathrm{M}$ $\mathrm{KOH}, 300 \mathrm{mOsm}$ ) for cell-attached recordings. We pharmacologically isolated action potential (AP)-dependent $\mathrm{GABA}_{\mathrm{A}}$-receptor-mediated sIPSCs by adding blockers of glutamatergic transmission $(20 \mu \mathrm{M}$ DNQX and $30 \mu \mathrm{M}$ DL AP-5) and $\mathrm{GABA}_{\mathrm{B}}$ receptors (1 $\mu \mathrm{M}$ CGP55845A) to the bath solution. To assess $\mathrm{AP}$-independent $\mathrm{GABA}_{\mathrm{A}}$-receptor-mediated transmission (mIPSCs), we added $0.5 \mu \mathrm{M}$ TTX to block $\mathrm{Na}^{+}$channels. Neurons were held at $-60 \mathrm{mV}$. All data were obtained from neurons with an access resistance $\left(R_{a}\right)$ further of $\leq 15 \mathrm{M} \Omega$ and a maximum change of $\mathrm{R}_{\mathrm{a}}$ of $<20 \%$ during the entire recording, as monitored by frequent $10 \mathrm{mV}$ pulses. We recorded spontaneous AP firing of CeA neurons in cell-attached configuration in current-clamp mode in aCSF. Serotonin's effects on intrinsic membrane properties and excitability of CeA neurons were determined in aCSF using current-clamp mode and a step protocol comprising $500 \mathrm{~ms}$ hyperpolarizing and depolarizing steps (10 pA steps), starting from $-120 \mathrm{pA}$ as previously described (Roberts et al., 2019; Suárez et al., 2019). 
Drugs

We purchased serotonin, WAY161503, SB2420840, 8-OH-DPAT, AP-5, CGP55845A, and DNQX from Tocris Bioscience, ethanol from Remet, and TTX from Biotium. Chemicals other than these were purchased from Sigma Millipore. Stock solutions of all drugs were prepared in either distilled water or DMSO and applied to the bath solution to achieve final concentrations. All drugs were applied by bath perfusion.

\section{Tissue preparation for ISH}

Male rats (3-4) from each treatment group (naive, dependent, and withdrawn) were anesthetized using isoflurane and perfused with ice-cold PBS/Z-fix (Fisher Scientific). Brains were dissected and immersion-fixed in Z-fix for $24 \mathrm{~h}$ at $4^{\circ} \mathrm{C}$, cryoprotected in sterile $30 \%$ sucrose in PBS for $24-48 \mathrm{~h}$ at $4^{\circ} \mathrm{C}$ or until brains sank, flash frozen in prechilled isopentane on dry ice, and stored at $-80^{\circ} \mathrm{C}$. Brains were then sliced on a cryostat in $20-\mu \mathrm{m}$-thick sections through the CeA, mounted on SuperFrost Plus slides (Fisher Scientific, 1255015), and stored at $-80^{\circ} \mathrm{C}$

ISH

We performed ISH using RNAscope fluorescent multiplex kit (ACD, 320850) under RNase-free conditions as previously described (Wolfe et al., 2019). First, a target retrieval pretreatment protocol was performed as outlined in the RNAscope pretreatment user manual (ACD, document \#320535). Briefly, slides were submerged in target retrieval buffer $(\mathrm{ACD}, 322000)$ at $95-98^{\circ} \mathrm{C}$ for $10 \mathrm{~min}$, immediately washed in distilled water, dehydrated in $100 \%$ ethanol (storage at $-80^{\circ} \mathrm{C}$ if required), and lastly incubated in Protease IV for $20 \mathrm{~min}$ at $40^{\circ} \mathrm{C}$. Next, the RNAScope Fluorescent Multiplex Reagent Kit User Manual (ACD, document \#320293) was followed with a final step where slides were mounted with DAPI-containing Vectashield (Thermo Fisher Scientific, NC9029229). The probes used from ACD Biotechne were as follows: negative control (320751), Htr2c (469321-C2), and Htr1a (404801-C2). One or two images (on average, 2 slices/animal) were acquired using a Carl Zeiss LSM 780 laser scanning confocal microscope $(40 \times$ oil immersion, $1024 \times 1024$, tile scanning of CeA, $5 \mu \mathrm{m} z$ stacks), and all settings were maintained within experiments during image acquisition. Brightness/contrast and pixel dilation are the same for all representative images shown per figures. Quantification was performed blind to treatment groups using the imaging software Fiji (Schindelin et al., 2012). Nuclei were identified based on the nuclear stain DAPI by Fiji or by visual inspection when necessary for images of the CeA. Nuclei were considered positive for the probe of interest if corresponding fluorescent signal was present after background subtraction (determined by the negative control probe). The percent of positive nuclei to total nuclei was calculated for each image and normalized to the control/naive group to indicate relative values. Next, Fiji was used to measure the mean optical densitometry of the fluorescent signal of each probe after background subtraction per image and normalized to the control/naive group.

\section{Data and statistical analysis}

Electrophysiology. We analyzed frequencies, amplitudes, and rise and decay times of sIPSCs/mIPSCs semiautomatically using MiniAnalysis software (Synaptosoft). Each event (for both sIPSCs/mIPSCs, minimum amplitude was set to $>5 \mathrm{pA}$ ) was visually confirmed. For analysis, we averaged sIPSC/mIPSC characteristics in 3 min bins. Drug effects were normalized to their own baseline (presented as control) before group analyses. We similarly analyzed cell-attached recordings semiautomatically using pClamp version 10 followed by a visual confirmation of each AP. Cells responding with an $\geq \pm 15 \%$ change of sIPSC/mIPSC or firing rate were considered as drug-sensitive. Effects of serotonin on intrinsic
B

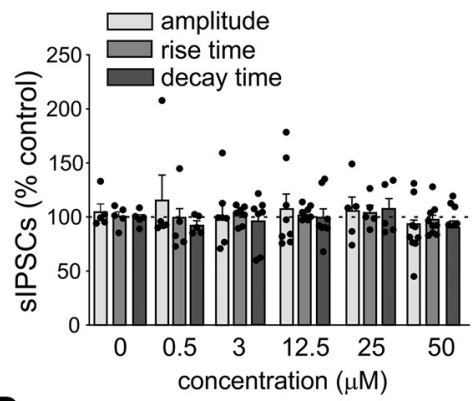

D

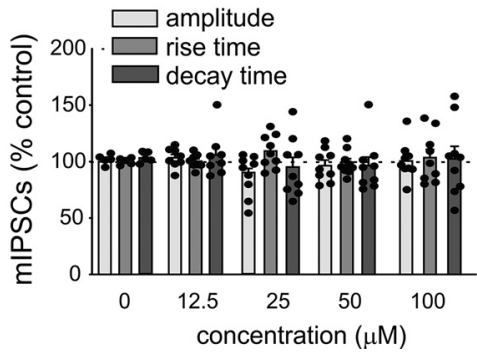

Figure 1. 5-HT increases AP-dependent and AP-independent CeA GABA release. Error bars indicate mean \pm SEM $<0.001$; compared with baseline control (dashed line) using one-sample $t$ tests. Differences between effects of individual 5-HT concentrations versus the zero-drug condition were calculated using a one-way ANOVA followed by a Dunnett's post hoc mean comparison: ${ }^{\#} p<0.05$; ${ }^{\#} p<0.01$; ${ }^{\# \# \#} p<0.0001$.

membrane properties and excitability were analyzed using the NeuroExpress software (version 19.4.09.) developed and provided by A. Szücs.

ISH. All analyses were performed on raw images, and outliers detected by Grubb's test were removed. Analysis of cell counts and densitometry was performed per image and normalized to the naive group indicating relative changes.

All data in this study are represented as mean \pm SEM. Statistical analysis and data graphing were performed using GraphPad Prism 8.0 (GraphPad). We set the criterion for statistical significance to $p<0.05$ and used one-sample $t$ tests to assess per se drug effects (i.e., statistical difference from control baseline before drug application) as in Figures $1 A-D, 4 B, C, E, F, 5 B, 6 E, F$, and $7 E, F$ and Table 1 . Of note, in case of significantly different SDs between treatments (Bartlett's test), we performed median split analyses (see Figs. $4 E, 5 B$ ). We used paired $t$ tests to evaluate 5-HT effects on passive and active membrane properties (see Fig. 2; Table 2). Statistical differences between more than two treatment groups were calculated using one-way ANOVA with appropriate post hoc mean comparisons as in Figure $1 A-D$ (Dunnett's), Figure $3 B-E, G, J$ (Dunnett's), Figure $4 B, C, E, F$ (Tukey's), Figure $5 B$ (Tukey's), Figure 6B, $C, E, F$ (Tukey's), and Figure $7 B, C, F, G$ (Tukey's). Sample sizes for each in experiment are given in the figure legends whereby $n$ denotes the total number of cells or images analyzed.

\section{Results}

\section{5-HT strongly increases both AP-dependent and AP-} independent CeA GABA release

Given the strong serotonergic innervation of the CeA (Vertes, 1991; Asan et al., 2013; Retson and Van Bockstaele, 2013; Linley et al., 2016) and the dense expression of 5-HT receptors in the CeA, we first examined 5-HT regulation of GABAergic synaptic transmission in the medial subdivision of the CeA, the major output region of the amygdalar complex. We tested different 5-HT concentrations $(0.5-50 \mu \mathrm{M})$ on pharmacologically isolated 
Table 1. Summary of 5-HT effects on CeA sIPSC and mIPSC characteristics in naive rats ${ }^{a}$

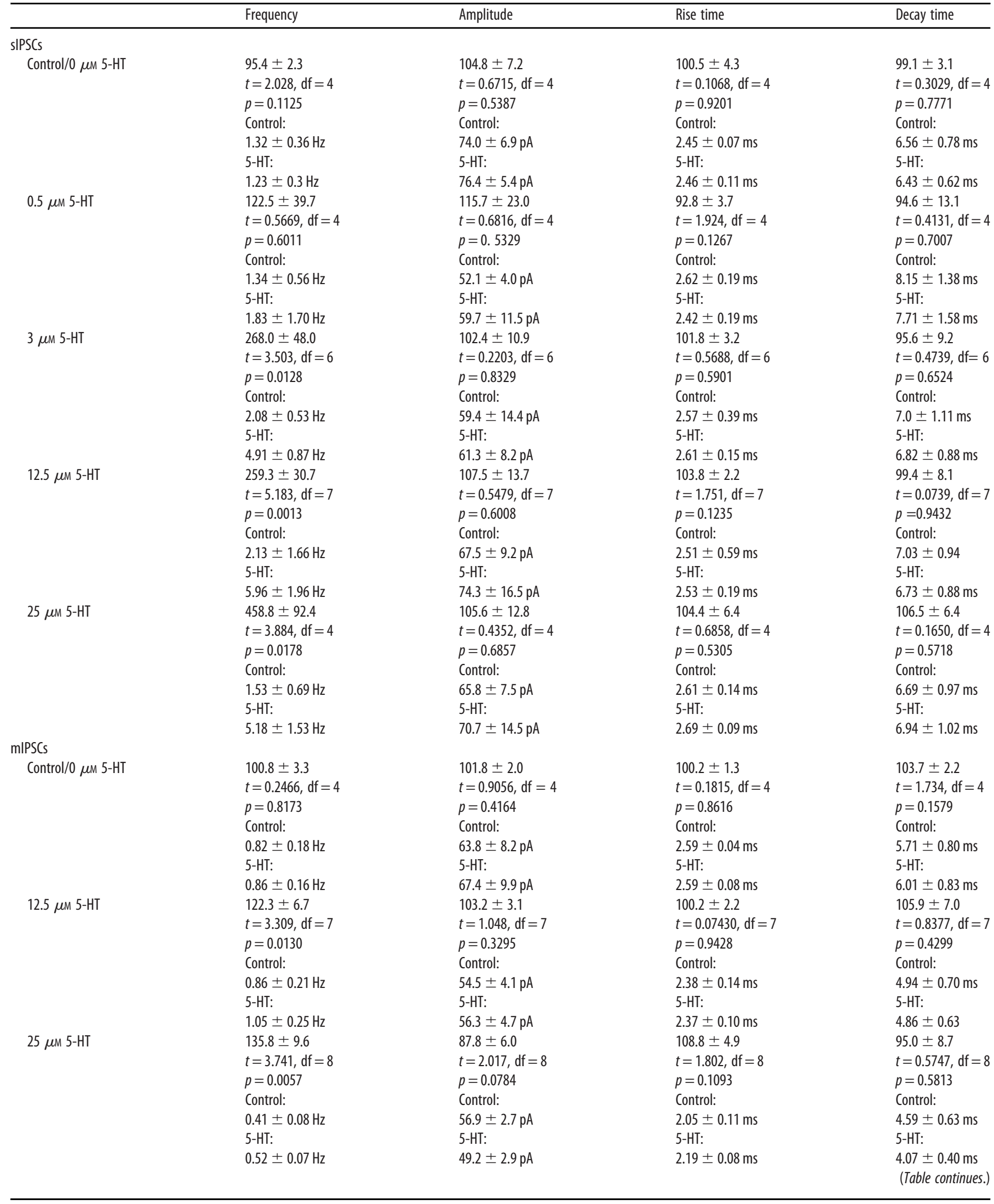


Table 1. Continued

\begin{tabular}{|c|c|c|c|c|}
\hline & Frequency & Amplitude & Rise time & Decay time \\
\hline \multirow[t]{7}{*}{$50 \mu \mathrm{m} 5-\mathrm{HT}$} & $141.5 \pm 5.8$ & $95.6 \pm 4.7$ & $98.8 \pm 3.7$ & $96.3 \pm 7.6$ \\
\hline & $t=7.147, \mathrm{df}=8$ & $t=0.7319, \mathrm{df}=8$ & $t=0.3115, \mathrm{df}=8$ & $t=0.4842, \mathrm{df}=8$ \\
\hline & $p<0.0001$ & $p=0.4851$ & $p=0.7634$ & $p=0.6412$ \\
\hline & Control: & Control: & Control: & Control: \\
\hline & $0.40 \pm 0.05 \mathrm{~Hz}$ & $59.3 \pm 3.1 \mathrm{pA}$ & $2.3 \pm 0.06 \mathrm{~ms}$ & $5.15 \pm 0.44 \mathrm{~ms}$ \\
\hline & 5-HT: & 5-HT: & 5-HT: & 5-HT: \\
\hline & $0.57 \pm 0.09 \mathrm{~Hz}$ & $56.9 \pm 3.3 \mathrm{pA}$ & $2.3 \pm 0.08 \mathrm{~ms}$ & $4.88 \pm 0.45 \mathrm{~ms}$ \\
\hline \multirow[t]{7}{*}{$100 \mu \mathrm{m} 5-\mathrm{HT}$} & $134.3 \pm 9.2$ & $100.7 \pm 5.4$ & $103.4 \pm 7.4$ & $102.4 \pm 11.1$ \\
\hline & $t=3.709, \mathrm{df}=8$ & $t=0.1219, \mathrm{df}=8$ & $t=0.4673, \mathrm{df}=8$ & $t=0.2189, \mathrm{df}=8$ \\
\hline & $p=0.0060$ & $p=0.9060$ & $p=0.6527$ & $p=0.8322$ \\
\hline & Control: & Control: & Control: & Control: \\
\hline & $0.40 \pm 0.22 \mathrm{~Hz}$ & $54.7 \pm 3.7 \mathrm{pA}$ & $2.37 \pm 0.17 \mathrm{~ms}$ & $4.72 \pm 0.53 \mathrm{~ms}$ \\
\hline & 5-HT: & 5-HT: & 5-HT: & 5-HT: \\
\hline & $0.52 \pm 0.08 \mathrm{~Hz}$ & $54.2 \pm 3.1 \mathrm{pA}$ & $2.37 \pm 0.08 \mathrm{~ms}$ & $4.83 \pm 0.59 \mathrm{~ms}$ \\
\hline
\end{tabular}

${ }^{a}$ Data are mean \pm SEM from raw values and normalized to baseline control, respectively, from at least 5 different cells from at least 4 different animals per group. Statistical significance from baseline was calculated using one-sample $t$ test.

spontaneous $\mathrm{GABA}_{\mathrm{A}}$ receptor-mediated inhibitory AP-dependent PSCs (sIPSCs) and AP-independent mIPSCs (12.5-100 $\mu \mathrm{M})$ in CeA neurons from naive rats. As shown in Figure $1 A$, we found that serotonin (5-HT) strongly and rapidly increased sIPSC frequency at concentrations $\geq 25 \mu \mathrm{M}$ compared with a zero-drug control condition (ANOVA, $F_{(5,33)}=8.871, p<$ 0.0001 ) without significantly affecting postsynaptic measures, including sIPSC amplitudes, and rise and decay times at any concentration tested (Fig. $1 B$ ), suggesting that 5 -HT modulates CeA network-dependent GABA release but not postsynaptic $\mathrm{GABA}_{\mathrm{A}}$ receptor function. 5-HT at concentrations $\geq 25 \mu \mathrm{M}$ also significantly increased mIPSC frequency, indicative of $5-\mathrm{HT}$ enhancing vesicular GABA release (Fig. 1C) compared with a zero-drug control condition (ANOVA, $\left.F_{(4,35)}=3.117, p=0.0271\right)$. 5-HT did not significantly alter mIPSC amplitudes or kinetics at any tested concentration (Fig. 1D), corroborating that 5-HT effects on CeA GABA release occur at the presynaptic site. All data for 5-HT effects on sIPSC and mIPSC characteristics are summarized in Table 1.

\section{Serotonin alters active and passive membrane properties of CeA neurons}

Next, we examined the effect of serotonin on passive and active membrane properties of CeA neurons by comparing current-voltage relationships in aCSF control conditions and in the presence of $50 \mu \mathrm{M}$ 5-HT (Fig. 2A). We found that 5-HT significantly altered slopes of current-voltage relationships (control: $0.4630 \pm 0.01944$ vs 5 -HT: $0.3820 \pm 0.01290$, assessed by a simple linear regression, $F=12.16$, degrees of freedom $(\mathrm{DFd})=570$, $p=0.0005$; Fig. $2 B$ ) and voltage sag slopes (control: $-0.068 \pm 0.005$ vs $5-\mathrm{HT}:-0.049 \pm 0.004$, assessed by a simple linear regression: $F=8.775$, degress of freedom $=475, p=0.0032$; Fig. $2 C$ ). In line, we found that 5 -HT significantly decreased membrane resistance, indicative of increased membrane conductance (control: $658.7 \pm$ $52.7 \mathrm{~m} \Omega$ vs 5 -HT: $549.7 \pm 45.1 \mathrm{~m} \Omega, t=2.737, \mathrm{df}=19, p=0.0131)$ and decreased AP threshold (control: $-47.72 ; \pm 0.78 \mathrm{mV}$ vs 5 -
A Control

$50 \mu \mathrm{M} 5-\mathrm{HT}$

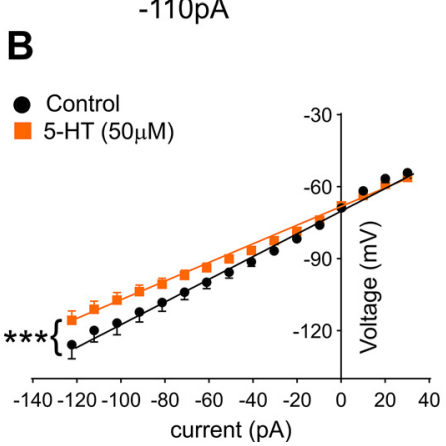

C
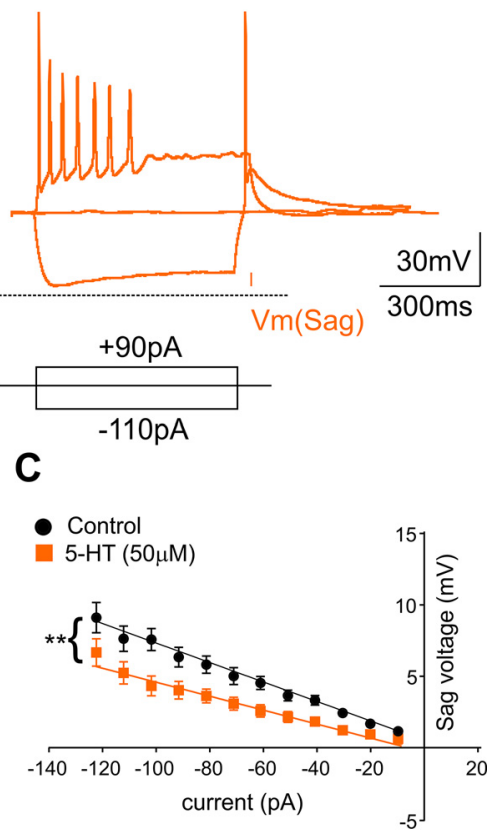

Figure 2. 5-HT alters active and passive membrane properties of CeA neurons. $A$, Representative traces for the current-voltage relationship of a CeA neuron in the absence (left, black trace) and in the presence of $50 \mu \mathrm{m} 5$-HT (right, orange trace) in response to a hyperpolarizing and depolarizing current step, respectively. Inset, Vertical bars represent the amplitude of the voltage sag. $\boldsymbol{B}$, Current-voltage relationship and $(\boldsymbol{C})$ current-voltage sag relationship in the absence (black circles) and in the presence of $50 \mu \mathrm{m} 5$-HT (orange squares). Data are mean \pm SEM from $n=20$ neurons. Significant differences between control conditions and during 5 -HT were assessed using paired $t$ test: ${ }^{* *} p<0.01 ;{ }^{* *} p<0.001$

HT: $-50.17 \pm 1.21 \mathrm{mV}, t=3.110, \mathrm{df}=19, p=0.0058)$. Last, we also found that 5 -HT altered the membrane time constant $\tau$ (control: $34.3 \pm 2.6$ vs 5 -HT: $28.0 \pm 2.2, t=2.805$, df $=19, p=$ $0.0113)$. We did not observe any significant changes in capacitance, rheobase, AP amplitudes, AP half-width, AP after-hyperpolarization, or cumulative number of APs after application of 5HT (all data are summarized in Table 2). Importantly, we did not observe any cell type-specific (low-threshold bursting, regular or late spiking neurons) (Chieng et al., 2006; Herman and Roberto, 2016) effects of 5-HT and thus pooled data from all recorded cells. 
Table 2. Summary of passive and membrane properties of CeA neurons in the absence and presence of $50 \mu \mathrm{M} 5-\mathrm{HT}^{a}$

\begin{tabular}{lcc}
\hline & Control & 5-HT $(50 \mu \mathrm{m})$ \\
\hline Membrane resistance & $658.7 \pm 52.7 \mathrm{~m} \Omega$ & $549.7 \pm 45.1 \mathrm{~m} \Omega^{*}$ \\
Capacitance & $70.8 \pm 3.1 \mathrm{pF}$ & $67.7 \pm 2.9 \mathrm{pF}$ \\
Time constant $\tau$ & $34.3 \pm 2.6$ & $28.0 \pm 2.2^{*}$ \\
Voltage sag slope & $0.4630 \pm 0.01944$ & $0.3820 \pm 0.01290^{* *}$ \\
Rheobase & $21.2 \pm 2.8 \mathrm{pA}$ & $21.5 \pm 3.7 \mathrm{pA}$ \\
AP threshold & $-47.72 \pm 0.78 \mathrm{mV}$ & $-50.17 \pm 1.21 \mathrm{mV} *$ \\
AP amplitude & $82.5 \pm 1.4 \mathrm{mV}$ & $82.2 \pm 1.7 \mathrm{mV}$ \\
AP half-width & $2.1 \pm 0.1 \mathrm{~ms}$ & $2.1 \pm 0.1 \mathrm{~ms}$ \\
AP after-hyperpolarization & $6.8 \pm 0.6 \mathrm{mV}$ & $6.6 \pm 0.6 \mathrm{mV}$ \\
Cumulative AP number & $2.9 \pm 0.7$ & $3.1 \pm 0.8$ \\
\hline
\end{tabular}

${ }^{a}$ Data are mean \pm SEM $(n=20)$. Membrane resistance was calculated from the hyperpolarizing steps of the current-voltage relationship. The time constant $\tau$ was calculated as an average determined from monoexponential fits of the initial parts of individual voltage responses elicited by negative current steps in currentclamp mode. The voltage sag was plotted against the level of the injected current, and the corresponding relationship was fitted using a linear function.

${ }^{*} p<0.05$; ${ }^{* *} p<0.01$; calculated using paired $t$ tests.

\section{Alcohol dependence-induced heightened GABA release persists into protracted withdrawal}

Elevated $\mathrm{GABA}_{\mathrm{A}}$ receptor-mediated signaling in the CeA is a hallmark of alcohol dependence across species (Roberto et al., 2004; Herman et al., 2016; Augier et al., 2018; Jimenez et al., 2019). Here, in line with our previous studies (Roberto et al., 2004; Khom et al., 2020), we found that chronic ethanol exposure significantly increased sIPSC frequencies (ANOVA, $F_{(2,155)}$ $=8.767, p=0.0002$; Fig. $3 A)$ in the CeA of both dependent $(1.93 \pm 0.18 \mathrm{~Hz}, n=49)$ and withdrawn $(2.45 \pm 0.38 \mathrm{~Hz}, n=36)$ rats compared with naive controls $(1.30 \pm 0.10 \mathrm{~Hz}, n=78$; Fig. $3 B$ ), but did not significantly affect sIPSC amplitudes (Fig. $3 C$ ), rise times (Fig. 3E), or decay times (Fig. 3F). Moreover, alcohol dependence also significantly increased mIPSC frequencies (ANOVA, $F_{(2,97)}=6.085, p=0.032$; Fig. $3 F$ ) in CeA neurons from dependent $(0.84 \pm 0.12 \mathrm{~Hz}, n=26$; Fig. $3 G)$ and withdrawn rats $(0.77 \pm 0.10 \mathrm{~Hz}, n=28)$ compared with naive controls $(0.52 \pm 0.05 \mathrm{~Hz}, n=53)$. We also found a significant effect of ethanol exposure on mIPSC amplitudes (ANOVA, $F_{(2,97)}=3.328$, $p=0.0397$; Fig. $3 H$ ), but a Tukey's post hoc mean comparison did not reveal significant differences between the groups. Furthermore, mIPSC rise times did not differ between groups, but chronic alcohol significantly prolonged mIPSC decay times $\left(\mathrm{ANOVA}, F_{(2,97)}=8.46\right.$, $p=0.0004)$ in dependent $(7.87 \pm 0.86 \mathrm{~ms}, n=26$; Fig. $3 I)$ and withdrawn $(7.76 \pm 0.63 \mathrm{~ms}, n=28)$ rats compared with naive controls $(5.46 \pm 0.33 \mathrm{~ms}, n=53$; Fig. $3 J)$, indicative of long-lasting presynaptic and postsynaptic neuroadaptations of CeA GABA signaling.

\section{Alcohol dependence blunts 5-HT-induced modulation of CeA synaptic network activity}

Recent studies indicate that chronic alcohol exposure increases excitatory transmission onto 5-HT projection neurons in the DRN (Lowery-Gionta et al., 2015), suggesting enhanced 5-HT release into brain areas connected to the DRN. Thus, we first determined how chronic alcohol exposure affects the 5-HTinduced increase of AP-dependent GABA transmission, reflecting the activity of the entire CeA neuronal network. Based on the robust and strong increase of synaptic GABA transmission induced by 5 -HT (see Figure $1 A$ ) we again used $50 \mu \mathrm{m} 5-\mathrm{HT}$ and found that chronic alcohol exposure blunted 5-HT regulation of CeA GABA signaling (Fig. 4A). Specifically, we found a main effect of chronic alcohol history on 5-HT-enhanced sIPSC frequencies (Fig. 4B; ANOVA, $F_{(2,31)}=4.249, p=0.0234$ ). A post hoc analysis (Tukey's) revealed that the 5-HT-induced increase of sIPSC frequency was significantly less pronounced in dependent rats compared with naive controls (naive: $724.9 \pm 126.4 \%$ vs dependent: $308.7 \pm 73.9 \%, p=0.0175)$ indicative of reduced sensitivity of the CeA GABAergic synaptic network to regulation by 5 -HT after chronic alcohol. To assess how long this dysregulation lasts, we tested the effects of 5-HT in CeA of withdrawn rats. Notably, the 5-HT-induced increase of sIPSC frequency in withdrawn rats did not differ from either naive or dependent rats, suggesting a transient effect, which might recover with longer alcohol withdrawal duration. Last, alcohol dependence did not significantly alter any 5-HT induced postsynaptic measures, including sIPSC amplitudes (ANOVA, $F_{(2,33)}=$ 0.4887, $p=0.6178$ ), rise times (ANOVA, $F_{(2,33)}=0.7820, p=$ 0.4658 ), or decay times (ANOVA, $F_{(2,33)}=0.1306, p=0.8780$ ) of sIPSCs as observed for naive rats (Fig. $4 C$ ).

\section{Alcohol withdrawal, but not alcohol dependence, dysregulates 5-HT modulation of CeA AP-independent GABA release}

Next, we determined whether chronic alcohol alters 5-HT modulation of AP-independent GABAergic synaptic transmission. As shown in Figure $4 D, 5$-HT $(50 \mu \mathrm{M})$ increased mIPSC frequency in dependent rats as in naive (naive: $141.5 \pm 5.8 \%, t=7.148$, $\mathrm{df}=8, p<0.0001$ vs dependent: $140.0 \pm 9.7 \%, t=4.137, \mathrm{df}=10$, $p=0.0020$; Fig. $4 E$ ), indicative of unaffected modulation of CeA vesicular GABA release by alcohol dependence. Interestingly, in CeA neurons from withdrawn rats, the overall effect of 5-HT on mIPSC frequency was not significantly different from baseline control. However, given significantly different SDs (Bartlett's test: 20.57, $p=0.0004$ ) between the treatment groups, a subsequent median split analysis revealed bidirectional 5-HT effects on mIPSC frequencies, such as 5-HT increased it in one subset $(160 \pm 23 \%, t=2.581$, df $=5, p=0.0494)$ while decreasing it in the other subset $(77 \pm 4, t=6.485, \mathrm{df}=4, p=0.0029)$. 5-HT did not alter postsynaptic mIPSC characteristics (amplitudes and kinetics) in any of the treatment groups (Fig. $4 F$ ), suggesting that neuroadaptations in the $5-\mathrm{HT}$ system regulating CeA GABA transmission predominantly occur at the presynaptic site.

\section{5-HT decreases spontaneous neuronal firing of CeA neurons} Our data indicate that 5 -HT induces a pronounced GABA release in the CeA. Given the mainly GABAergic nature of the $\mathrm{CeA}$, this increased GABAergic signaling in response to $5-\mathrm{HT}$ might thus stem from an activation of intra-CeA GABAergic neurons. Thus, we next assessed the effect of 5-HT on spontaneous AP firing of CeA neurons. Importantly, spontaneous baseline firing did not significantly differ between naive $(2.1 \pm$ $0.2 \mathrm{~Hz}, n=9$, ANOVA, $\left.F_{(2,27)}=0.6718, p=0.5191\right)$ dependent $(1.6 \pm 0.2 \mathrm{~Hz}, n=11)$ or withdrawn rats $(2.4 \pm 0.8 \mathrm{~Hz}, n=10)$. As shown in Fig. 5A; 5-HT strongly reduced the neuronal firing rate of CeA neurons in naive $(-68.5 \pm 26 \%, t=2.648, \mathrm{df}=8$, $p=0.0293$; Fig. $5 B)$ and dependent $(-61 \pm 15.7 \%, t=3.915$, $\mathrm{df}=10, p=0.0029$; Fig. $5 B$ ) rats, suggesting that 5 -HT overall decreases CeA excitability stemming from increased GABA release onto CeA neurons. Interestingly, the overall firing rate of CeA neurons from withdrawn rats was not significantly changed in the presence of 5-HT (Fig. 5B). However, based on significantly different SDs (Bartlett's test: 15.33, $p=0.0041$ ), we performed a post hoc median split analysis revealing bidirectional 5HT effects on AP firing, such as 5-HT increased it in one subset $(142 \pm 50 \%, t=2.824, \mathrm{df}=4, p=0.0477)$ and decreased it in the other subset $(-87 \pm 10 \%, t=8.484, \mathrm{df}=4, p=0.0011)$, suggesting that protracted withdrawal from chronic ethanol disrupts 5-HTmediated inhibition of neuronal firing. 
A
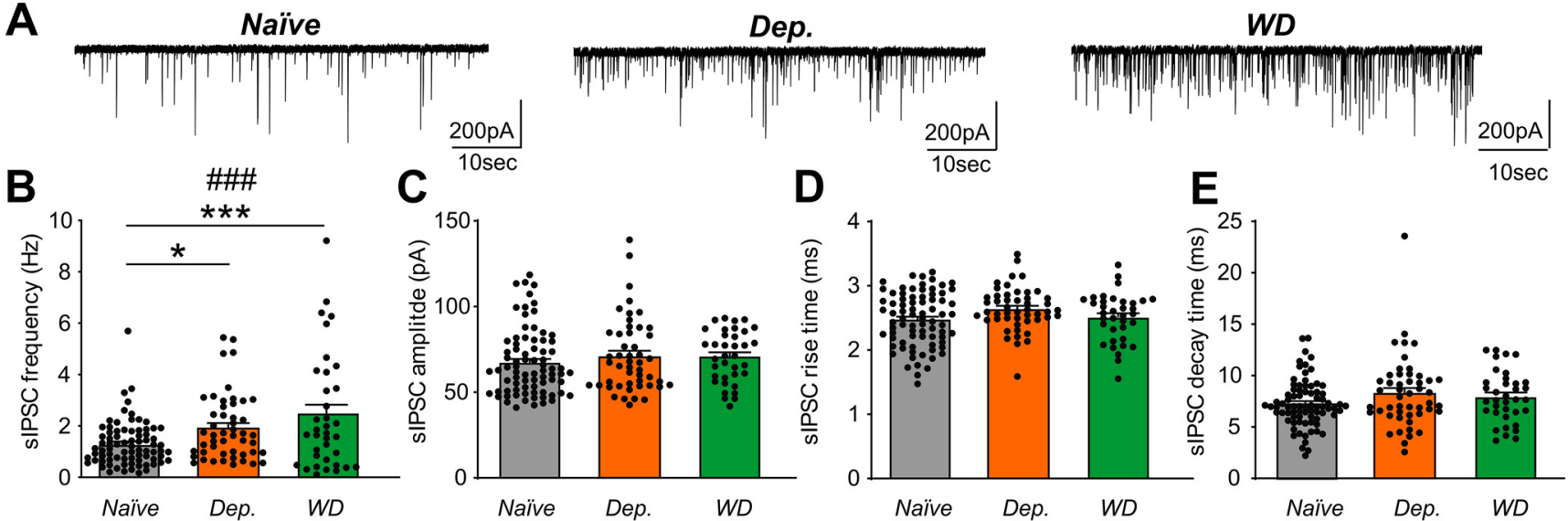

$\mathbf{F}$

Naïve
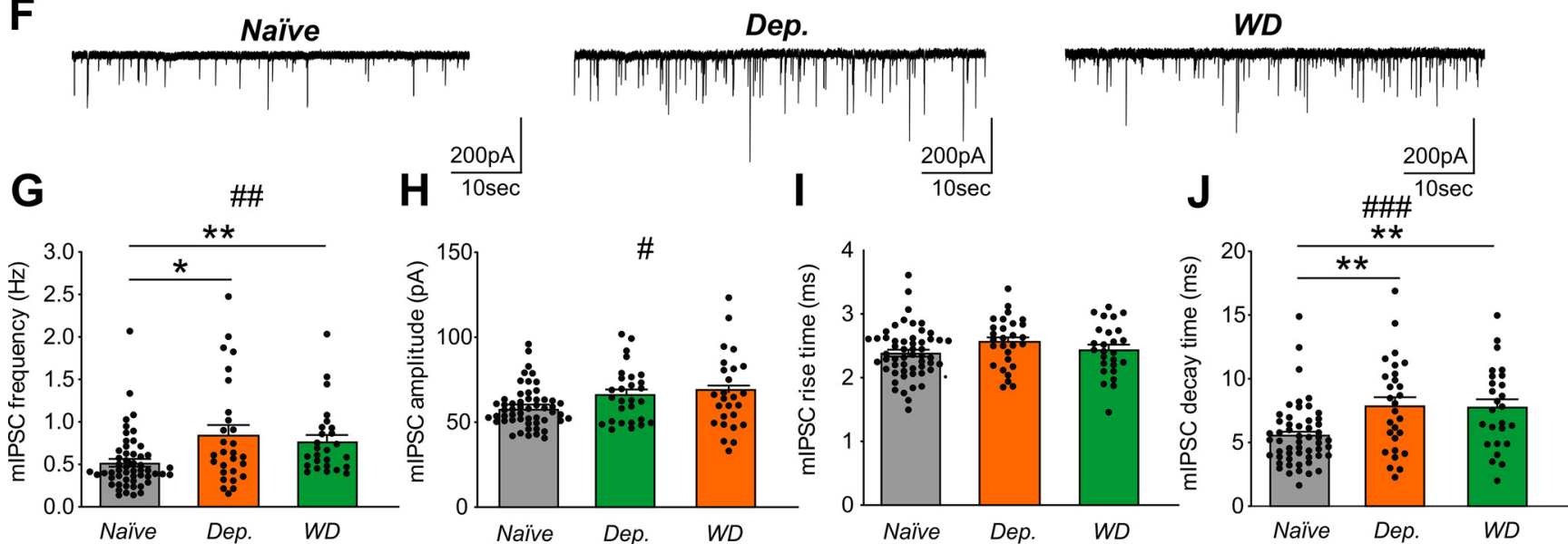

Figure 3. Chronic alcohol exposure and withdrawal increase CeA GABA release. A, Representative sIPSC recordings from CeA neurons from naive, dependent (Dep), and withdrawn (WD) rats. Error bars indicate mean \pm SEM of SIPSC $(\boldsymbol{B})$ frequencies, $(\boldsymbol{C})$ amplitudes, $(\boldsymbol{D})$ rise times, and $(\boldsymbol{E})$ decay times. $\boldsymbol{F}$, Representative mIPSC recordings from naive, dependent, and withdrawn rats. Error bars indicate mean \pm SEM of mIPSC $(\boldsymbol{G})$ frequencies, $(\boldsymbol{H})$ amplitudes, $(\boldsymbol{I})$ rise times, and $(\boldsymbol{l})$ decay times. Differences between groups were calculated using one-way ANOVA $\left({ }^{\#} p<0.05 ;{ }^{\# \#} p<0.01 ;{ }^{\# \#} p<0.001\right)$ followed by a Dunnett's post hoc mean comparison $\left({ }^{*} p<0.05 ;{ }^{* *} p<0.01 ;{ }^{* *} p<0.001\right)$.

\section{5-HT1A regulates vesicular CeA GABA release despite chronic alcohol exposure}

5-HT1A signaling has been strongly implicated in alcohol dependence associated behaviors, and 5-HT1A receptors are abundantly expressed in the CeA (Asan et al., 2013) likely functioning as heteroreceptors reducing transmitter release (Starke et al., 1989; Nautiyal and Hen, 2017). Thus, we examined the consequences of chronic alcohol exposure on both CeA Htrla mRNA expression and 5-HT1A-mediated regulation of GABAergic synaptic transmission. As shown in Figure $6 A-C$, ISH, performed using RNAscope (ACD Biotechne) technology, revealed no difference in cells expressing Htrla or density of Htrla mRNA in the $\mathrm{CeA}$ between treatment groups (i.e., naive, dependent, and withdrawn; percent cells expressing: ANOVA, $F_{(2,30)}=0.3300, p=$ 0.7215, densitometry: ANOVA, $\left.F_{(2,28)}=0.2289, p=0.7968\right)$. Moreover, we also found that selective 5-HT1A activation using 8-OH-DPAT $(10 \mu \mathrm{M})$ decreased CeA mIPSC frequencies to comparable extents in all groups (ANOVA, $F_{(8,69)}=0.6091, p=0.7972$; naive: $60.3 \pm 5.5 \%, \quad t=7.254, \quad \mathrm{df}=7, \quad p=0.0002$; dependent: $69.6 \pm 5.5 \%, t=5.491, \mathrm{df}=8, p=0.0006$; withdrawn: $63.8 \pm 6.1 \%$, $t=5.974, \quad \mathrm{df}=8, p=0.0003$; Fig. $6 D, E)$, while neither mIPSC amplitudes nor kinetics were significantly altered (Fig. $6 F$ ). These data suggest a robust 5-HT1A-mediated regulatory role of CeA presynaptic GABA release, which is not compromised by alcohol dependence.
Alcohol dependence disrupts 5-HTR2C signaling

5-HT2C plays a pivotal role in anxiety-related behaviors, as activation of amygdalar 5-HT2C induces anxiety-like behavior in rodents, while 5-HT2C antagonism results in anxiolysis (Campbell and Merchant, 2003; Overstreet et al., 2006; Règue et al., 2019). Thus, we determined whether alcohol dependence alters 5-HT2C expression and function. Importantly, we identified a comparable expression pattern of $H \operatorname{tr} 2 c \mathrm{mRNA}$ in the CeA of all treatment groups (Fig. $7 A-C$; percent cells expressing: ANOVA, $F_{(2,34)}=0.2137, p=0.8087$; densitometry: ANOVA, $\left.F_{(2,34)}=0.4025, p=0.6718\right)$, indicating that alcohol dependence and withdrawal do not affect $H t r 2 c$ mRNA expression. Our electrophysiological studies revealed that activating CeA 5-HT2C using the selective agonist WAY161503 (30 $\mu \mathrm{M})$ robustly increased both sIPSC $(171.0 \pm 17.87 \%, t=3.973 \mathrm{df}=8$; Fig. $7 D$, $E)$ and mIPSC frequency $(144.4 \pm 6.2 \%, t=7.120, \mathrm{df}=3, p=$ 0.0057 ) in naive rats without affecting either sIPSC (Fig. $7 F$ ) or mIPSC amplitudes, rise times, or decay times. However, the 5HT2C agonist did not increase sIPSC frequency in either dependent $(99.51 \pm 7.34 \%, t=0.06629$; $\mathrm{df}=11, p=0.9483)$ or in withdrawn rats $(93.88 \pm 5.97 \%, t=1.026 \mathrm{df}=11, p=0.3268$; Fig. $7 D, E)$. In agreement, we found that the selective 5 -HT2C antagonist SB2420840 (100 nM) decreased sIPSC frequency only in naive rats $(70.00 \pm 6.79 \%, t=4.417 \mathrm{df}=7, p=0.0031$; Fig. $7 D, F)$, revealing a basal regulation of the CeA activity by 5 -HT2C 

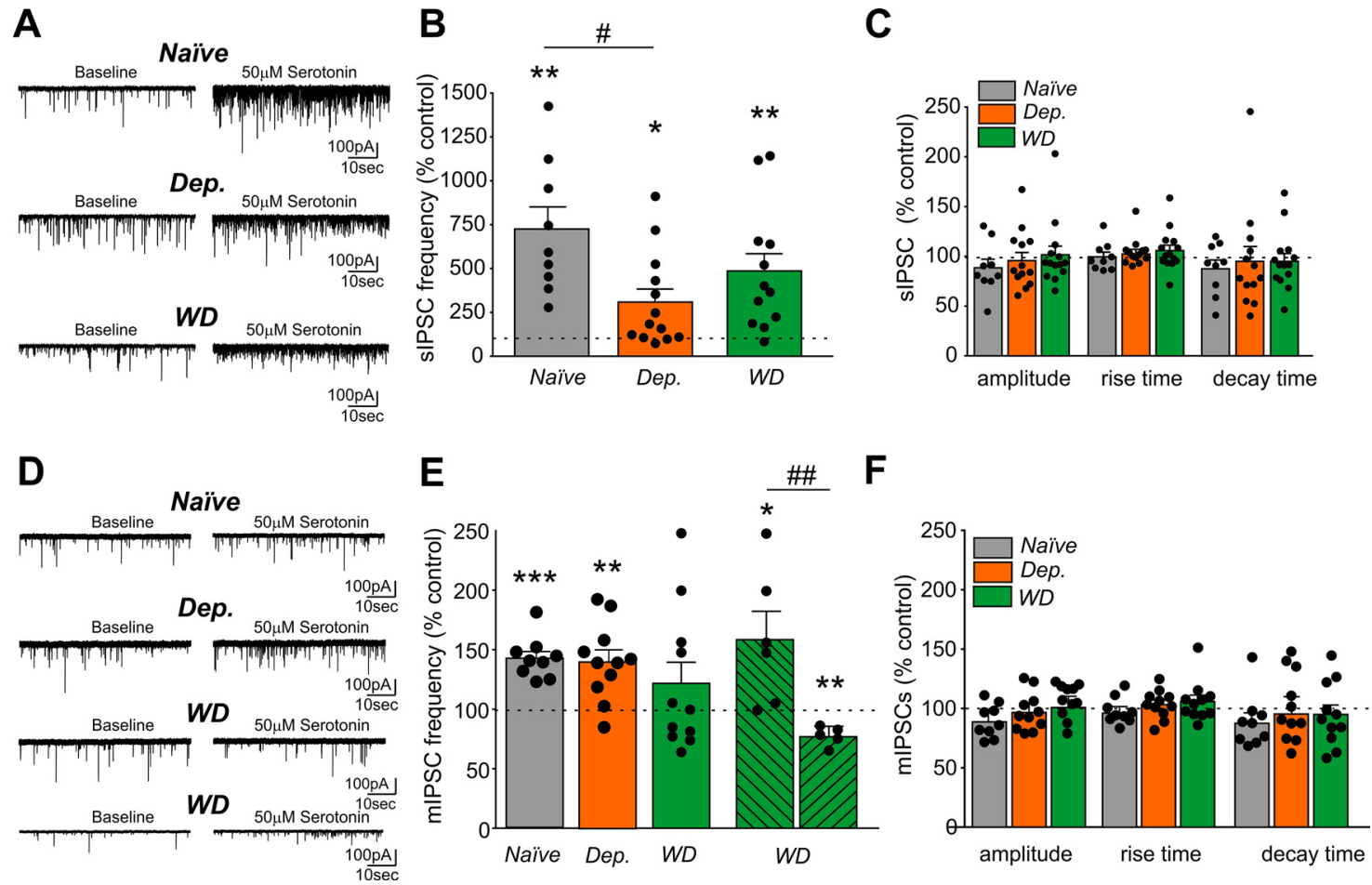

Figure 4. Alcohol dependence and withdrawal dysregulate 5-HT regulation of CeA GABA transmission. $A$, Representative sIPSCs under baseline control conditions (left) and during superfusion of 5-HT $(50 \mu \mathrm{m})$ from the indicated experimental groups. Bars represent the effects of 5-HT (50 $\mu \mathrm{m})$ on sIPSC $(\boldsymbol{B})$ frequency and $(\boldsymbol{C})$ amplitude, and rise and decay times in CeA neurons from naive, dependent, and withdrawn rats. $\boldsymbol{D}$, Representative mIPSCs under baseline control conditions and during superfusion of 5 -HT (50 $\mu \mathrm{m}$ ) from the indicated experimental groups. Bars represent the effects of 5-HT $(50 \mu \mathrm{m})$ on mIPSC $(\boldsymbol{E})$ frequency and $(\boldsymbol{F})$ amplitude, and rise and decay times in CeA neurons from the indicated groups. A median split analysis (shaded, green bars) for data on 5 -HT effects on mIPSC frequencies in withdrawn rats ( $\boldsymbol{E}$, green bar) has been performed. Differences between experimental groups were calculated using a one-way ANOVA and Tukey's multiple comparisons test $\left({ }^{\#} p<0.05 ;{ }^{* \#} p<0.01\right)$, and differences to baseline control conditions (dashed line) were calculated using one-sample $t$ tests $\left({ }^{*} p<0.05\right.$; ${ }^{* *} p<0.01$; $\left.{ }^{* * *} p<0.01\right)$. Data for 5 -HT effects $(50 \mu \mathrm{m})$ on SIPSCs and mIPSCs, respectively, are taken from Figure $1 A-D$. Error bars indicate mean \pm SEM from $n=9$ to 13 cells.

A
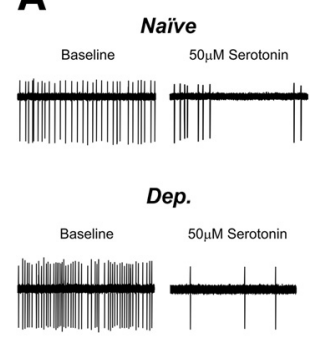

$10 \underline{\text { sec }}$

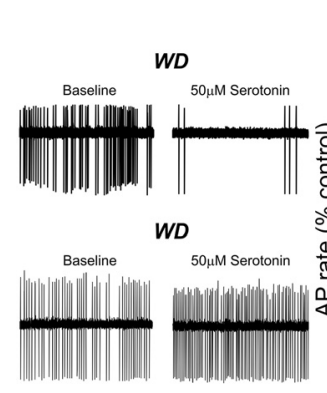

$10 \underline{\text { sec }}$

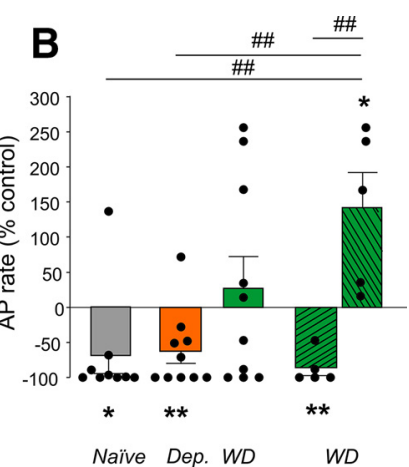

Figure 5. 5-HT decreases spontaneous AP firing of CeA neurons from naive and dependent rats but has split/ mixed effects on spontaneous firing in withdrawn rats. $A$, Representative cell-attached recordings from CeA neurons under control conditions and during superfusion of $50 \mu \mathrm{m} 5-\mathrm{HT}$ from the indicated animal groups. $\boldsymbol{B}$, Error bars indicate mean \pm SEM, depicting the effect of 5-HT on neuronal firing compared with baseline from 9 to 11 neurons (dashed line). One-sample $t$ test: ${ }^{*} p<0.05 ;{ }^{* *} p<0.01$. A median split analysis was performed for data obtained from CeA neurons from withdrawn rats (green, shaded bars). Differences between groups were assessed using a one-way ANOVA with a Tukey's post hoc mean comparison: ${ }^{\#} p<0.01$.

signaling. The 5-HT2C antagonist did not alter sIPSC frequency in either dependent $(94.46 \pm 8.96 \% ; t=0.6180 \mathrm{df}=7, p=0.5561)$ or withdrawn rats $(105.4 \pm 8.81 \%, t=0.6135 \mathrm{df}=7, p=0.5590$; Fig. $7 F$ ) and did not affect sIPSC amplitudes or kinetics in any of the groups. Thus, although alcohol dependence and withdrawal did not alter $H t r 2 c$ mRNA expression, they induced a profound and long-lasting change of 5-HT2C function in the CeA. Specifically, CeA network-driven GABA transmission becomes insensitive to regulation by both 5-HT2C agonism and antagonism with alcohol dependence, and it does not recover in protracted withdrawal. In summary, our data implicate a basal regulation of CeA GABA signaling via 5-HT2C in naive, which is lost with alcohol dependence and protracted withdrawal.

\section{Discussion}

The CeA, the major output area of the amygdalar complex, is a key mediator of negative emotional states associated with alcohol dependence (Wise and Koob, 2014; Koob and Volkow, 2016; Roberto et al., 2020) and is highly sensitive to both chronic and acute alcohol (Roberto et al., 2003, 2004). Elevated GABA signaling in the CeA is considered a hallmark of alcohol dependence across species (Roberto et al., 2004; Herman and Roberto, 2016; Augier et al., 2018; Jimenez et al., 2019). Importantly, the CeA and the DRN are reciprocally connected (Vertes, 1991; Linley et al., 2016), and there is compelling evidence for heightened DRN activity following chronic alcohol exposure in mice (Lowery-Gionta et al., 2015). Thus, given dense expression of 5-HT receptors in the CeA (Asan et al., 2013), we here examined potential neuroadaptations of CeA 5-HT signaling induced by alcohol dependence and withdrawal using ex vivo slice electrophysiology and ISH.

Our study unravels a specific vulnerability of the CeA 5-HT system to both chronic alcohol exposure and protracted alcohol 
withdrawal. Specifically, we identified distinct, long-lasting neuroadaptations of CeA 5-HT signaling associated with alcohol dependence as well as distinct neuroadaptations resulting from protracted alcohol withdrawal. Since the CeA is predominantly GABAergic, we first studied 5-HT modulation of the two main forms of pharmacologically isolated $\mathrm{GABA}_{\mathrm{A}}$ receptormediated transmission: (1) AP-dependent $\mathrm{GABA}_{\mathrm{A}}$ receptor-mediated transmission (sIPSCs) reflecting the activity of the entire synaptic CeA network; and (2) AP-independent monosynaptic transmission (mIPSCs) mediated via vesicular GABA release.

5-HT strongly increased CeA AP-dependent GABA transmission (sIPSCs) of naive rats, but its efficacy was significantly reduced in alcohol-dependent rats, suggesting that alcohol dependence dampens the sensitivity of the GABAergic synaptic network to exogenous 5-HT. Alternatively, this reduced efficacy of exogenous 5-HT might also reflect a saturated 5-HT receptor system in the CeA. In such a scenario, 5-HT receptors would be maximally activated by elevated levels of endogenous CeA 5 -HT originating from increased DRN activity (Lowery-Gionta et al., 2015). Interestingly, 5-HT effects on $\mathrm{CeA}$ GABA transmission in withdrawn rats did not significantly differ from either naive or dependent rats, suggesting that the apparent loss of efficacy of exogenous 5-HT action is transient and might fully recover with more prolonged withdrawal. Our study also implicates that 5-HT regulates $\mathrm{CeA}$ activity mainly via presynaptic mechanisms. 5-HT increased vesicular GABA release in the $\mathrm{CeA}$ of naive, dependent, and withdrawn rats to a similar extent. However, in the CeA of withdrawn rats 5-HT also decreased GABA release in a subset of $\mathrm{CeA}$ neurons. Interestingly, we could not find a clear correlation between CeA cell-type (i. e., low-threshold, regular spiking and late spiking neurons) (Chieng et al., 2006) and divergent 5-HT effects (increase/decrease). Thus, given that changes of CeA activity in response to 5-HT likely originate from activation of both excitatory and inhibitory 5-HT receptor subtypes, the observed bidirectional modulation of vesicular CeA GABA release may result from neuroadaptations specifically induced by protracted withdrawal at the presynaptic site. These neuroadaptations could involve mechanisms, such as recruitment/upregulation of distinct inhibitory 5-HT1 subtypes in distinct circuits, downregulation of excitatory 5-HT subtypes, or alterations of intracellular signaling pathways, resulting in differential 5-HT regulation of vesicular GABA release.

Our studies also suggest that 5-HT increases the excitability of CeA neurons in naive rats indicated by flattened slopes of the current-voltage-relationships in the presence of 5-HT and a decreased AP threshold. In addition, 5-HT decreased membrane resistance, indicating elevated membrane conductance. Previous studies (e.g., in motoneurons) suggested that these excitatory 5HT effects occur via activation of different 5 -HT receptors that in turn modulate various ion channels (Perrier et al., 2013). Interestingly, 5-HT almost completely abolished spontaneous AP firing of $\mathrm{CeA}$ neurons in naive rats, suggesting that, despite increased neuronal excitability, the large 5-HT-induced GABA release inhibits firing. Importantly, we found a similar 5-HT regulation of AP firing in neurons from dependent rats but again bidirectional modulation of neuronal firing in alcohol withdrawn rats. Of note, despite marked elevation of inhibitory GABAergic signaling in dependent and withdrawn rats compared with naive controls (see also Roberto et al., 2004; Khom et al., 2020), we did not find any significant differences in spontaneous firing rates between the treatment groups. Hence, one might speculate that the elevated 

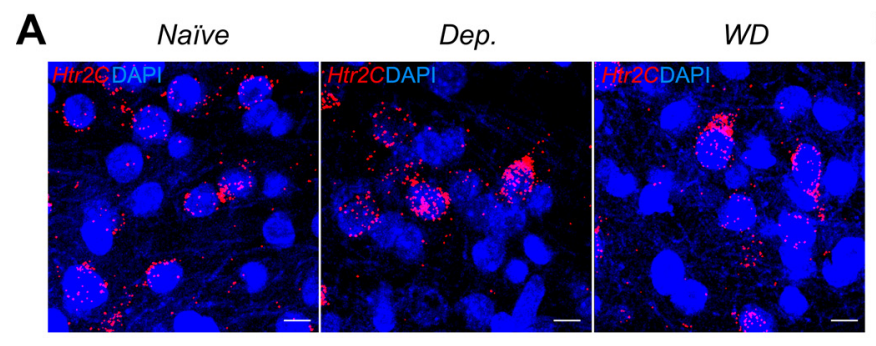

B

C
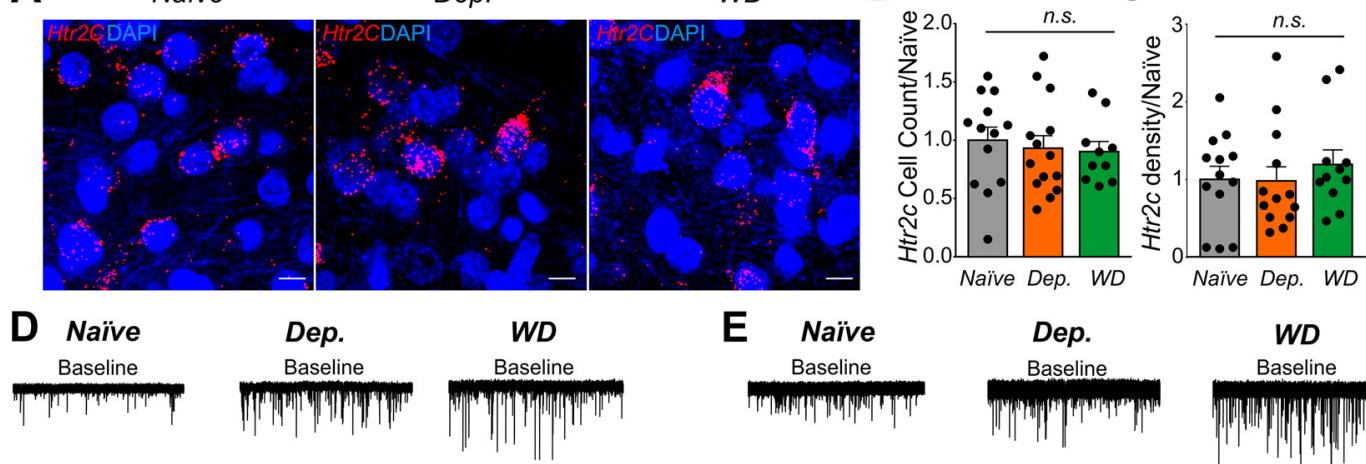

E
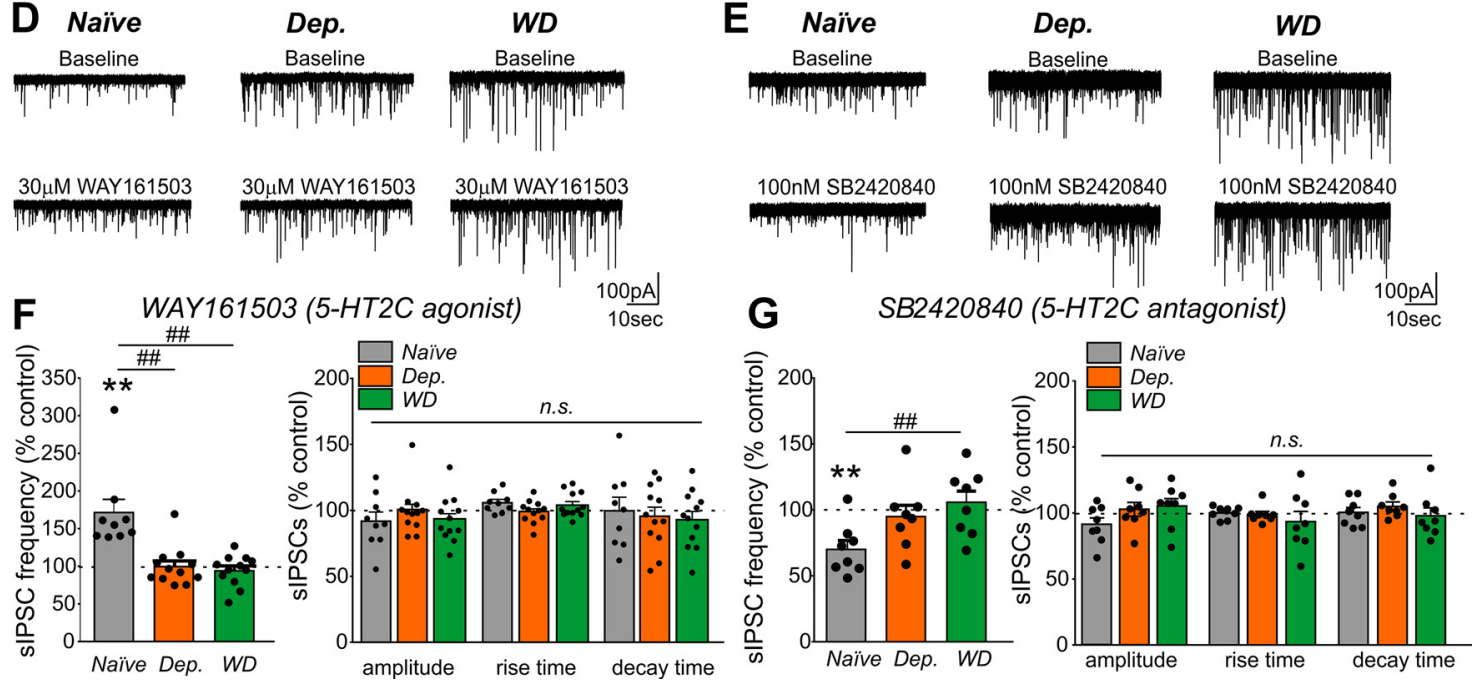

Figure 7. Alcohol dependence and withdrawal disrupt CeA 5-HT2C receptor signaling. A, Representative images of Htr2C (red) and DAPI (blue) in the CeA are shown for naive, dependent (Dep), and withdrawn (WD) groups. Scale bar, $10 \mu \mathrm{m}$. Error bars indicate mean \pm SEM of $(\boldsymbol{B})$ the percent cells expressing Htr2c relative to naive in CeA for the indicated groups, and (C, $\boldsymbol{D})$ optical density of $\mathrm{Htr} 2 \mathrm{C}$ relative to the naive in the CeA for the indicated groups. Representative sIPSC recordings under baseline control conditions and during superfusion of either the 5-HT2C agonist (30 $\mu \mathrm{m}$ WAY161503) (E) or the 5-HT2C antagonist (100 nм SB2420840) in the indicated experimental group. Error bars indicate mean \pm SEM and depict changes of sIPSC frequencies, amplitudes, and current kinetics in the presence of $(\boldsymbol{F})$ the 5-HT2C agonist or $(\boldsymbol{G})$ the 5-HT2C antagonist compared with baseline. Differences between groups were calculated (D) using a oneway ANOVA (Tukey's post hoc mean comparison) and differences from baseline were assessed with one-sample $t$ tests: ${ }^{* *} p<0.01$; ${ }^{\# \#} p 0.01$. n.s., not significant.

CeA GABAergic tone characteristic to alcohol dependence stems from local and extra-CeA inputs.

Among the 14 different 5-HT-gated receptors (McCorvy and Roth, 2015), multiple studies identified 5-HT1A and 5-HT2C as key players in addictive behaviors, including AUD (Müller et al., 2007; Marcinkiewcz et al., 2016), and both are densely expressed in the CeA (Asan et al., 2013). It has been reported that 5-HT1A mediates alcohol-induced aggressive behaviors in mice (Miczek et al., 1998), and selective 5-HT1A agonists decrease alcohol drinking of monkeys (McKenzie-Quirk and Miczek, 2003) and alcohol preference in Wistar rats (Schreiber et al., 1993). In addition, Htrla polymorphisms have also been recently associated with substance use disorder, including AUD (Donaldson et al., 2016) and increased susceptibility to depression and related mood disorders (Le François et al., 2008). 5-HT1A receptors are abundantly expressed in the brain, including the CeA (Asan et al., 2013), serving as both autoreceptors and heteroreceptors (limiting either serotonin or other neurotransmitter release), and thus play a critical role in negative feedback (Starke et al., 1989; Nautiyal and Hen, 2017). Our study revealed that alcohol dependence and protracted alcohol withdrawal did not compromise CeA 5-HT1A function or Htrla expression. We report that a selective 5-HT1A agonist decreased CeA GABA release in all treatment groups to similar extents, suggesting that 5-HT1A signaling might be a homeostatic regulator of CeA synaptic transmission. Importantly, decreasing inhibitory inputs onto CeA neurons could also result in disinhibition; but given that elevated CeA GABA transmission mediates the negative emotional state of alcohol dependence (Roberto et al., 2004; Herman et al., 2016;
Augier et al., 2018; Jimenez et al., 2019), targeting 5-HT1A to reduce $\mathrm{CeA}$ GABAergic tone could have therapeutic potential for the treatment of AUD.

Last, our study also identified long-lasting, dysregulated CeA 5-HT2C signaling following alcohol dependence. Increased 5HT2C signaling in the BNST has been implicated in the etiology of AUD and associated affective and anxiety disorders (Marcinkiewcz et al., 2015). In addition, increased density of amygdalar 5-HT2C has been found in genetic models of alcohol preference (Pandey et al., 1996). In line with this, the selective 5-HT2 agonist lorcaserin reduced alcohol intake in alcohol-preferring rats, further corroborating the critical role of 5-HT2C signaling in alcohol dependence (Rezvani et al., 2014). Here, we found that activation of the 5-HT2C using a selective agonist robustly increased CeA GABA release likely via a presynaptic mechanism in naive rats. Conversely, the 5-HT2C antagonist decreased CeA GABA release, indicative of endogenous 5-HT signaling via 5 -HT2C receptors regulating CeA synaptic activity. Notably, this regulatory function of CeA activity by the 5-HT2C was abolished by chronic alcohol exposure, whereas Htr2c mRNA expression was not affected by either chronic alcohol exposure or subsequent protracted withdrawal. However, the ISH is limited in its abilities to detect subcellular localization of mRNA that may be trafficked to distal processes outside of the nucleus. Additionally, it is well accepted that mRNA levels do not necessarily reflect levels of translated protein, and protein localization and activity may also impact function/signaling without altering mRNA levels. Furthermore, there is growing evidence that $\mathrm{Htr} 2 c$ undergoes RNA editing in neuropsychiatric 
disease, such as PTSD (Baratta et al., 2016), and such Htr2c alternative splicing can cause the resulting 5-HT2C isoform to be constitutively active in the absence of ligands (Tanaka and Watanabe, 2019). Chronic ethanol vapor exposure in mice (C57BL6) also increases levels of edited isoforms of Htr2c mRNA (Watanabe et al., 2014) in the nucleus accumbens, which is associated with increased ethanol drinking. Thus, it is tempting to speculate that similar changes of Htr2c might occur in the CeA. Alternatively, heightened DRN activity following chronic alcohol exposure (Lowery-Gionta et al., 2015) accompanied by potentially decreased amygdalar serotonin transporter levels (Mantere et al., 2002; Storvik et al., 2007, 2008) suggests increased 5-HT levels in the CeA. In such a scenario, CeA 5HT2C would be already saturated; therefore, application of an agonist would not result in further increases in GABA signaling.

Collectively, our study provides detailed insights into modulation of CeA activity by the 5-HT system and how alcohol dependence and protracted alcohol withdrawal dysregulate CeA 5-HT signaling at multiple levels. Notably, this is the first time we are reporting neuroadaptations in rat CeA 5-HT signaling originating from protracted alcohol withdrawal. Often, it is assumed that protracted withdrawal reverses maladaptive processes stemming from chronic drug exposure. However, AUD is not conceptualized as the mere result of repeated alcohol intake but as a complex disorder shaped by the negative emotional states associated with the absence of alcohol (Koob, 2013, 2015). Thus, it is conceivable that alcohol dependence-induced maladaptive processes last into protracted withdrawal, but it is also important to understand that protracted drug abstinence induces neuroadaptations in various neurochemical signaling systems. Hence, this study further expands our knowledge of CeA cellular mechanisms involved in the pathophysiology of alcohol dependence and withdrawal.

\section{References}

Asan E, Steinke M, Lesch KP (2013) Serotonergic innervation of the amygdala: targets, receptors, and implications for stress and anxiety. Histochem Cell Biol 139:785-813.

Augier E, Barbier E, Dulman RS, Licheri V, Augier G, Domi E, Barchiesi R, Farris S, Nätt D, Mayfield RD, Adermark L, Heilig M (2018) A molecular mechanism for choosing alcohol over an alternative reward. Science 360:1321-1326.

Baratta MV, Kodandaramaiah SB, Monahan PE, Yao J, Weber MD, Lin PA, Gisabella B, Petrossian N, Amat J, Kim K, Yang A, Forest CR, Boyden ES, Goosens KA (2016) Stress enables reinforcement-elicited serotonergic consolidation of fear memory. Biol Psychiatry 79:814-822.

Belmer A, Patkar OL, Pitman KM, Bartlett SE (2016) Serotonergic neuroplasticity in alcohol addiction. Brain Plast 1:177-206.

Bonkale WL, Turecki G, Austin MC (2006) Increased tryptophan hydroxylase immunoreactivity in the dorsal raphe nucleus of alcohol-dependent, depressed suicide subjects is restricted to the dorsal subnucleus. Synapse 60:81-85.

Campbell BM, Merchant KM (2003) Serotonin 2C receptors within the basolateral amygdala induce acute fear-like responses in an open-field environment. Brain Res 993:1-9.

Charnay Y, Léger L (2010) Brain serotonergic circuitries. Dialogues Clin Neurosci 12:471-487.

Chieng BC, Christie MJ, Osborne PB (2006) Characterization of neurons in the rat central nucleus of the amygdala: cellular physiology, morphology, and opioid sensitivity. J Comp Neurol 497:910-927.

Donaldson ZR, le Francois B, Santos TL, Almli LM, Boldrini M, Champagne FA, Arango V, Mann JJ, Stockmeier CA, Galfalvy H, Albert PR, Ressler KJ, Hen R (2016) The functional serotonin 1a receptor promoter polymorphism, rs6295, is associated with psychiatric illness and differences in transcription. Transl Psychiatry 6:e746.

Dos Santos RG, Bouso JC, Alcázar-Córcoles MÁ, Hallak JE (2018) Efficacy, tolerability, and safety of serotonergic psychedelics for the management of mood, anxiety, and substance-use disorders: a systematic review of systematic reviews. Expert Rev Clin Pharmacol 11:889-902.

Feinn R, Nellissery M, Kranzler HR (2005) Meta-analysis of the association of a functional serotonin transporter promoter polymorphism with alcohol dependence. Am J Med Genet B Neuropsychiatr Genet 133B:79-84.

Garcia-Garcia AL, Canetta S, Stujenske JM, Burghardt NS, Ansorge MS, Dranovsky A, Leonardo ED (2018) Serotonin inputs to the dorsal BNST modulate anxiety in a 5-HT1A receptor-dependent manner. Mol Psychiatry 23:1990-1997.

Gilpin NW, Herman MA, Roberto M (2015) The central amygdala as an integrative hub for anxiety and alcohol use disorders. Biol Psychiatry 77:859869.

Herman MA, Contet C, Roberto M (2016) A functional switch in tonic GABA currents alters the output of central amygdala corticotropin releasing factor receptor-1 neurons following chronic ethanol exposure. J Neurosci 36:10729-10741.

Herman MA, Roberto M (2016) Cell type-specific tonic GABA signaling in the rat central amygdala is selectively altered by acute and chronic ethanol. Addict Biol 21:72-86.

Jimenez VA, Herman MA, Cuzon Carlson VC, Walter NA, Grant KA, Roberto M (2019) Synaptic adaptations in the central amygdala and hypothalamic paraventricular nucleus associated with protracted ethanol abstinence in male rhesus monkeys. Neuropsychopharmacology 44:982993.

Khom S, Steinkellner T, Hnasko TS, Roberto M (2020) Alcohol dependence potentiates substance $\mathrm{P} /$ neurokinin-1 receptor signaling in the rat central nucleus of amygdala. Sci Adv 6:eaaz1050.

Koob GF (2008) A role for brain stress systems in addiction. Neuron 59:1134.

Koob GF (2013) Addiction is a reward deficit and stress surfeit disorder. Front Psychiatry 4:72.

Koob GF (2015) The dark side of emotion: the addiction perspective. Eur J Pharmacol 753:73-87.

Koob GF, Volkow ND (2016) Neurobiology of addiction: a neurocircuitry analysis. Lancet Psychiatry 3:760-773.

Kranzler HR, Armeli S, Tennen H, Covault J (2013) 5-HTTLPR genotype and daily negative mood moderate the effects of sertraline on drinking intensity. Addict Biol 18:1024-1031.

Krystal JH, Webb E, Cooney NL, Kranzler HR, Southwick SW, Heninger GR, Charney DS (1996) Serotonergic and noradrenergic dysregulation in alcoholism: m-chlorophenylpiperazine and yohimbine effects in recently detoxified alcoholics and healthy comparison subjects. Am J Psychiatry 153:83-92.

Lappalainen J, Long JC, Eggert M, Ozaki N, Robin RW, Brown GL, Naukkarinen H, Virkkunen M, Linnoila M, Goldman D (1998) Linkage of antisocial alcoholism to the serotonin 5-HT1B receptor gene in 2 populations. Arch Gen Psychiatry 55:989-994.

Lê AD, Tomkins DM, Sellers EM (1996) Use of serotonin (5-HT) and opiatebased drugs in the pharmacotherapy of alcohol dependence: an overview of the preclinical data. Alcohol Alcohol 31 Suppl 1:27-32.

Le François B, Czesak M, Steubl D, Albert PR (2008) Transcriptional regulation at a HTR1A polymorphism associated with mental illness. Neuropharmacology 55:977-985.

Lejoyeux M (1996) Use of serotonin (5-hydroxytryptamine) reuptake inhibitors in the treatment of alcoholism. Alcohol Alcohol 31 Suppl 1:69-75.

Linley SB, Olucha-Bordonau F, Vertes RP (2016) Pattern of distribution of serotonergic fibers to the amygdala and extended amygdala in the rat. J Comp Neurol 525:116-139.

Lowery-Gionta EG, Marcinkiewcz CA, Kash TL (2015) Functional alterations in the dorsal raphe nucleus following acute and chronic ethanol exposure. Neuropsychopharmacology 40:590-600.

Mantere T, Tupala E, Hall H, Särkioja T, Räsänen P, Bergström K, Callaway J, Tiihonen J (2002) Serotonin transporter distribution and density in the cerebral cortex of alcoholic and nonalcoholic comparison subjects: a whole-hemisphere autoradiography study. Am J Psychiatry 159:599-606.

Marcinkiewcz CA, Dorrier CE, Lopez AJ, Kash TL (2015) Ethanol induced adaptations in 5-HT2c receptor signaling in the bed nucleus of the stria terminalis: implications for anxiety during ethanol withdrawal. Neuropharmacology 89:157-167

Marcinkiewcz CA, Lowery-Gionta EG, Kash TL (2016) Serotonin's complex role in alcoholism: implications for treatment and future research. Alcohol Clin Exp Res 40:1192-1201. 
McCorvy JD, Roth BL (2015) Structure and function of serotonin G proteincoupled receptors. Pharmacol Ther 150:129-142.

McKenzie-Quirk SD, Miczek KA (2003) 5-HT1A agonists: alcohol drinking in rats and squirrel monkeys. Psychopharmacology (Berl) 167:145-152.

Miczek KA, Hussain S, Faccidomo S (1998) Alcohol-heightened aggression in mice: attenuation by 5-HT1A receptor agonists. Psychopharmacology (Berl) 139:160-168.

Müller CP, Carey RJ, Huston JP, De Souza Silva MA (2007) Serotonin and psychostimulant addiction: focus on 5-HT1A-receptors. Prog Neurobiol 81:133-178.

Nautiyal KM, Hen R (2017) Serotonin receptors in depression: from A to B. F1000Res 6:123.

Overstreet DH, Knapp DJ, Angel RA, Navarro M, Breese GR (2006) Reduction in repeated ethanol-withdrawal-induced anxiety-like behavior by site-selective injections of 5-HT1A and 5-HT2C ligands. Psychopharmacology (Berl) 187:1-12.

Pandey SC, Lumeng L, Li TK (1996) Serotonin2C receptors and serotonin2C receptor-mediated phosphoinositide hydrolysis in the brain of alcoholpreferring and alcohol-nonpreferring rats. Alcohol Clin Exp Res 20:1038-1042.

Perrier JF, Rasmussen HB, Christensen RK, Petersen AV (2013) Modulation of the intrinsic properties of motoneurons by serotonin. Curr Pharm Des 19:4371-4384.

Pettinati HM, Kranzler HR, Madaras J (2003) The status of serotonin-selective pharmacotherapy in the treatment of alcohol dependence. Recent Dev Alcohol 16:247-262.

Règue M, Poilbout C, Martin V, Franc B, Lanfumey L, Mongeau R (2019) Increased 5-HT2C receptor editing predisposes to PTSD-like behaviors and alters BDNF and cytokines signaling. Transl Psychiatry 9:100.

Retson TA, Van Bockstaele EJ (2013) Coordinate regulation of noradrenergic and serotonergic brain regions by amygdalar neurons. J Chem Neuroanat 52:9-19.

Rezvani AH, Cauley MC, Levin ED (2014) Lorcaserin, a selective 5-HT(2C) receptor agonist, decreases alcohol intake in female alcohol preferring rats. Pharmacol Biochem Behav 125:8-14.

Roberto M, Madamba SG, Moore SD, Tallent MK, Siggins GR (2003) Ethanol increases GABAergic transmission at both pre- and postsynaptic sites in rat central amygdala neurons. Proc Natl Acad Sci USA 100:20532058.

Roberto M, Madamba SG, Stouffer DG, Parsons LH, Siggins GR (2004) Increased GABA release in the central amygdala of ethanol-dependent rats. J Neurosci 24:10159-10166.

Roberto M, Kirson D, Khom S (2020) The role of the central amygdala in alcohol dependence. Cold Spring Harb Perspect Med Advance online publication. Retrieved January 27, 2020. doi: 10.1101/cshperspect. a039339.

Roberts AJ, Khom S, Bajo M, Vlkolinsky R, Polis I, Cates-Gatto C, Roberto M, Gruol DL (2019) Increased IL-6 expression in astrocytes is associated with emotionality, alterations in central amygdala GABAergic transmission, and excitability during alcohol withdrawal. Brain Behav Immun $82: 188-202$.
Schindelin J, Arganda-Carreras I, Frise E, Kaynig V, Longair M, Pietzsch T, Preibisch S, Rueden C, Saalfeld S, Schmid B, Tinevez JY, White DJ, Hartenstein V, Eliceiri K, Tomancak P, Cardona A (2012) Fiji: an opensource platform for biological-image analysis. Nat Methods 9:676-682.

Schreiber R, Opitz K, Glaser T, De Vry J (1993) Ipsapirone and 8-OH-DPAT reduce ethanol preference in rats: involvement of presynaptic 5-HT1A receptors. Psychopharmacology (Berl) 112:100-110.

Spanagel R, Noori HR, Heilig M (2014) Stress and alcohol interactions: animal studies and clinical significance. Trends Neurosci 37:219-227.

Starke K, Göthert M, Kilbinger H (1989) Modulation of neurotransmitter release by presynaptic autoreceptors. Physiol Rev 69:864-989.

Storvik M, Haukijärvi T, Tupala E, Tiihonen J (2008) Correlation between the SERT binding densities in hypothalamus and amygdala in Cloninger type 1 and 2 alcoholics. Alcohol Alcohol 43:25-30.

Storvik M, Tiihonen J, Haukijärvi T, Tupala E (2007) Amygdala serotonin transporters in alcoholics measured by whole hemisphere autoradiography. Synapse 61:629-636.

Suárez J, Khom S, Alén F, Natividad LA, Varodayan FP, Patel RR, Kirson D, Arco R, Ballesta A, Bajo M, Rubio L, Martin-Fardon R, Rodríguez de Fonseca F, Roberto M (2019) Cessation of fluoxetine treatment increases alcohol seeking during relapse and dysregulates endocannabinoid and glutamatergic signaling in the central amygdala. Addict Biol 25:e12813.

Tanaka M, Watanabe Y (2019) RNA editing of serotonin 2C receptor and alcohol intake. Front Neurosci 13:1390.

Tunstall BJ, Kirson D, Zallar LJ, McConnell SA, Vendruscolo JC, Ho CP, Oleata CS, Khom S, Manning M, Lee MR, Leggio L, Koob GF, Roberto M, Vendruscolo LF (2019) Oxytocin blocks enhanced motivation for alcohol in alcohol dependence and blocks alcohol effects on GABAergic transmission in the central amygdala. PLoS Biol 17:e2006421.

Vertes RP (1991) A PHA-L analysis of ascending projections of the dorsal raphe nucleus in the rat. J Comp Neurol 313:643-668.

Watanabe Y, Yoshimoto K, Tatebe H, Kita M, Nishikura K, Kimura M, Tanaka $\mathrm{M}$ (2014) Enhancement of alcohol drinking in mice depends on alterations in RNA editing of serotonin 2C receptors. Int J Neuropsychopharmacol 17:739751.

Wise RA, Koob GF (2014) The development and maintenance of drug addiction. Neuropsychopharmacology 39:254-262.

Wolfe SA, Sidhu H, Patel RR, Kreifeldt M, D'Ambrosio SR, Contet C, Roberto M (2019) Molecular, morphological, and functional characterization of corticotropin-releasing factor receptor 1-expressing neurons in the central nucleus of the amygdala. eNeuro 6:ENEURO.0087-19.2019.

Yohros A, Ford J, Hinojosa MS (2018) Dating violence victimization and substance use: the role of a serotonin transporter gene polymorphism (5HTTLPR). Drug Alcohol Depend 189:178-186.

Yoshimoto K, Ueda S, Kato B, Takeuchi Y, Kawai Y, Noritake K, Yasuhara M (2000) Alcohol enhances characteristic releases of dopamine and serotonin in the central nucleus of the amygdala. Neurochem Int 37:369-376.

Yoshimoto K, Watanabe Y, Tanaka M, Kimura M (2012) Serotonin2C receptors in the nucleus accumbens are involved in enhanced alcohol-drinking behavior. Eur J Neurosci 35:1368-1380. 